\title{
Medical devices and the Middle East: market, regulation, and reimbursement in Gulf Cooperation Council states
}

This article was published in the following Dove Press journal:

Medical Devices: Evidence and Research

20 November 2014

Number of times this article has been viewed

\section{Jason J Howard}

Division of Paediatric Orthopaedics, Department of Surgery, Sidra Medical and Research Center, Doha, Qatar
Correspondence: Jason J Howard Department of Surgery, c/o Sidra Medical and Research Center, PO Box 26999,

Doha, Qatar

Tel +974 44042274

Fax +974 44041969

Email jhoward@sidra.org
Abstract: With some of the richest economies in the world, the Gulf Cooperation Council (GCC) is undergoing rapid growth not only in its population but also in health care expenditure. Despite the GCC's abundance of hydrocarbon-based wealth, the drivers of the medical device industry in the GCC are still in flux, with gains yet to be made in areas of infrastructure, regulation, and reimbursement. However, the regional disease burden, expanding health insurance penetration, increasing privatization, and a desire to attract skilled expatriate health care providers have led to favorable conditions for the medical device market in the GCC. The purpose of this article is to investigate the current state of the GCC medical device industry, with respect to market, regulation, and reimbursement, paying special attention to the three largest medical device markets: Saudi Arabia, the United Arab Emirates, and Qatar. The GCC would seem to represent fertile ground for the development of medical technologies, especially those in line with the regional health priorities of the respective member states.

Keywords: medical devices, regulation, reimbursement, Middle East

\section{Brief history of the Gulf Cooperation Council}

On May 25, 1981, an economic union of six Arab states (Saudi Arabia, the United Arab Emirates or UAE [comprising Abu Dhabi, Dubai, Sharjah, Ajman, Umm al-Quwain, Ras al-Khaimah, and Fujairah], Qatar, Kuwait, Oman, and Bahrain) adjacent to the waters of the Arabian Gulf was created with the intention of establishing relations that fostered the advancement of research and development, joint venture projects, regional security, interstate trade relations, regional identity, and ultimately, a common currency (Figure 1). Despite the commonalities in language, lineage, religion, and geography, these member states have significant differences with respect to their regional identity and legal, administrative, and economic performance. ${ }^{1}$

Similar to the vast majority of Middle Eastern countries, the economies of the member states of the Gulf Cooperation Council (GCC) are primarily hydrocarbonbased, and thus fluctuate with global prices for oil and natural gas. The extraordinary growth in these countries shows no signs of slowing, with the health care market alone expected to rise at an annual rate of $11 \%$ to US $\$ 43.9$ billion by 2015 , increasing from approximately US\$25.6 billion in $2010 .^{2}$ Despite this regional wealth, GCC states such as the State of Qatar, which is currently the richest country in the world, with a gross domestic product per capita of US\$93,825 compared with US\$51,749 for the United States, ${ }^{3}$ are making concerted efforts to diversify their economies beyond hydrocarbons to those that are more knowledge-based. As a result, major investment in areas relating to research and innovation are being made, including in the 


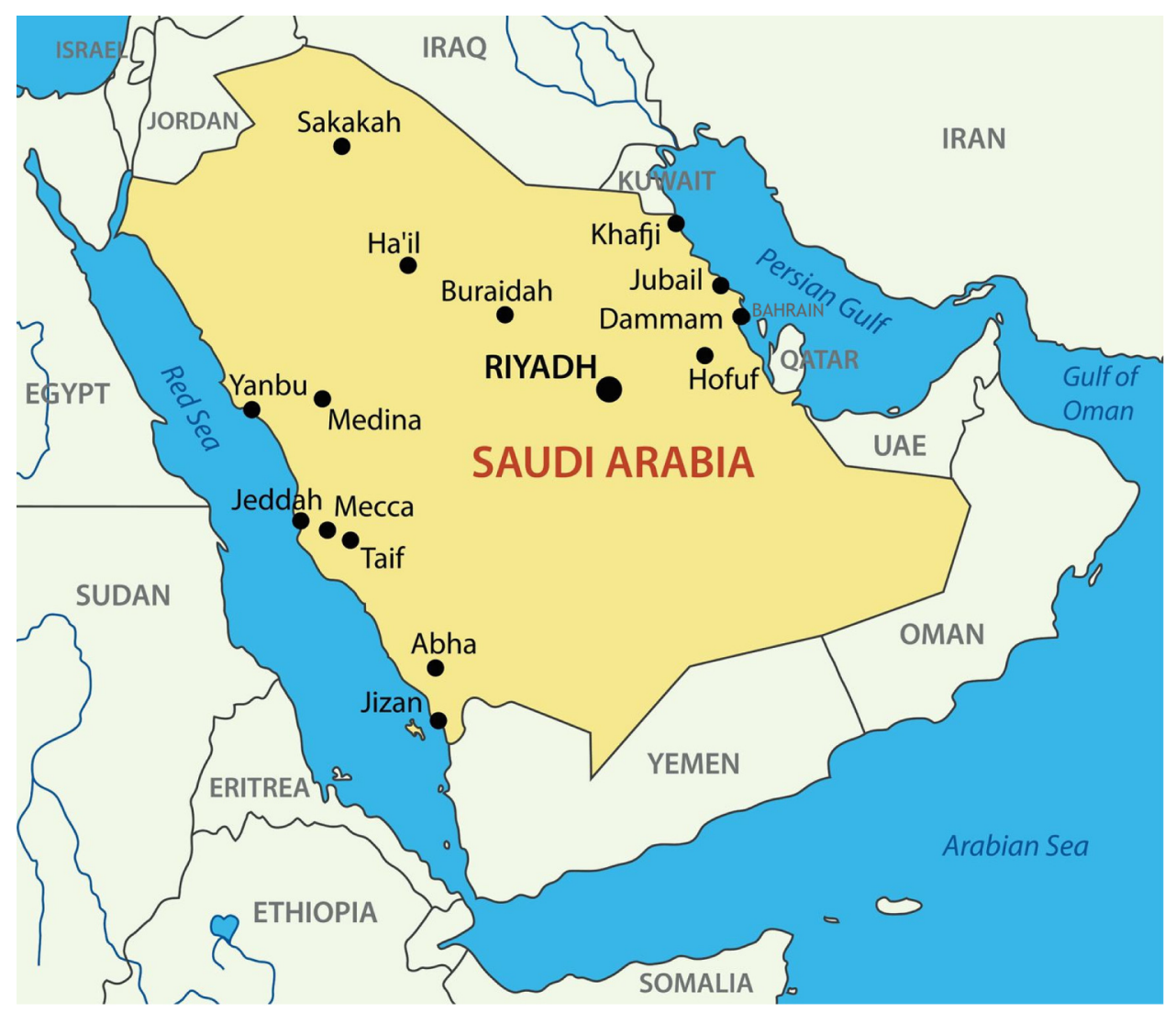

Figure I Map of the Gulf Cooperation Council Countries (Saudi Arabia, UAE [United Arab Emirates], Qatar, Kuwait, Oman) and their place in the world. Note: Copyright : http://www.I23rf.com/profile_pavalena. Reproduced from I23rf.com. Vector - Kingdom of Saudi Arabia. Pavalena. Available from: http://www.I23rf.com/ photo 14459935 kingdom-of-saudi-arabia.html. Accessed November II, 2014. ${ }^{38}$

health and biomedical engineering sectors. High per capita income rates in the GCC have allowed for a significant investment in health care expenditure that has resulted in a steady improvement of indicators such as infant mortality and life expectancy. ${ }^{4}$ Despite these gains, the incidence of so-called "lifestyle diseases" (eg, type 2 diabetes, obesity, and cardiovascular disease) linked to an sedentary lifestyle has increased significantly, putting additional burdens on health care systems and promoting demand for health care services, including medical devices.

At this time, there is a paucity of peer-reviewed literature that describes the drivers and regulatory aspects related to the medical device industry in the Middle East. The purpose of this article was to investigate the state of the GCC medical device industry, with respect to market, regulation, and reimbursement, with special attention paid to the three largest medical device markets: Saudi Arabia, the UAE, and Qatar. In addition to their having the largest market share, another reason to review these three states was to highlight the different levels of medical device regulation maturity within the GCC. In this regard, Saudi Arabia has the most established regulatory framework, followed by the UAE, and last, Qatar, with its system still in the early stages of development.

The specific objectives of this review are to define the prevailing disease states within the GCC as drivers for the medical device market; to investigate the existing medical device market and future trends for medical device needs in the GCC; to investigate the existing regulatory framework within the GCC, how it differs between member states, and the existing barriers/opportunities to/for medical technology approval; to investigate the prevailing system of reimbursement within the GCC health care systems and associated stakeholders; and to define the state of medical device innovation initiatives from within the GCC and identify future trends.

\section{Demographics of the GCC}

The GCC demographic profile is rapidly changing as the population explodes to accommodate the frenetic pace of construction, megaprojects, and demand for services. The United Nations Development Program, for example, reports population estimates for the State of Qatar to be 1.4 million in 2008; a number that has burgeoned to more than 2 million 
in $2014 .^{5}$ In a pattern common throughout the GCC member states, the majority of their populations are nonnational. For example, in the UAE, approximately $80 \%$ of their population of 5 million individuals are non-Emirati expatriates. ${ }^{6}$ This population increase is mainly a result of the influx of young immigrant laborers and a high fertility rate among the local population. ${ }^{7}$ To this point, continuing with the UAE example, $24 \%$ of the population is younger than 15 years, whereas only $6 \%$ are older than 50 years. ${ }^{5}$ For those in the $15-50$-year age group, it is anticipated that health-related pressures associated with musculoskeletal, cardiac, and obstetric disorders will need to be prioritized as the GCC expands its population base. There is, however, a shift in demographics occurring, with a slow but steady increase in the older age group that will have a significant effect on future health care expenditure and the need for advanced medical technologies. As health care spending is typically directly related to increases in population growth, the expectation for the medical device market in the GCC is very optimistic.

\section{Prevailing disease states}

The disease states inherent to the Arabian peninsula are influenced by three factors: increased personal and private wealth, which has been associated with an increased prevalence of so-called "lifestyle" diseases (eg, ischemic heart disease, stroke, type 2 diabetes, and obesity), ${ }^{8}$ the high rate of road traffic accidents and their associated morbidity and mortality (eg, musculoskeletal injuries, visceral injuries, and closedhead injuries) $;{ }^{9}$ and widespread consanguinity, leading to a rise in genetically recessive disorders and more common adult diseases with a genetic influence (eg, diabetes mellitus, hearing deficits, asthma, hypertension, and cancer). ${ }^{10}$ In fact, noncommunicable diseases are the most common causes of death. In Qatar, for example, injuries are the leading cause of death, followed by coronary artery disease, cancer, and diabetes-related diseases. ${ }^{11}$ Coupled with an aging population, these disease states represent significant drivers for the medical device market in the GCC.

\section{Obesity and nutrition-related diseases}

Fueled by increasing wealth, GCC countries are undergoing rapid urbanization associated with a relative decrease in available outdoor spaces for recreation and exercise. This situation has contributed to a prevailing lifestyle that is sedentary, with an increased prevalence of obesity. In Qatar, according to 2013 figures from the World Bank, 99\% of the populations lives in cities, with few areas dedicated to physical activity in proportion to its population size. ${ }^{12}$ Paradoxically, increased personal affluence has also resulted in a decline in nutrition, with a propensity toward fast food consumption and high caloric intake that is proportional to household income. ${ }^{13}$ This phenomenon, known as the "nutrition transition" (first noted in developed countries), is now a major problem leading to disease in emerging economies such as the GCC. ${ }^{14}$ For these states, in which more than $70 \%$ of the population is obese, an expected rise in related diseases such as type 2 diabetes (which is present in $23 \%$ of Qatari nationals), stroke, hypertension, and coronary artery disease is expected. ${ }^{8}$ This obesity trend is not only present in adults, as $25 \%-40 \%$ of children in the GCC are also obese. ${ }^{14}$ This is a staggering number that is much higher than the rate found in Western nations such as Australia and the United Kingdom. ${ }^{15}$

The obesity management market is expected to rise to US $\$ 140$ billion by 2017 in the United States alone. ${ }^{16}$ The high prevalence of obesity and its related diseases represents an opportunity for medical device penetration (eg, minimally invasive gastric banding) into the GCC market both for existing devices and for the development of new technologies within a motivated society with abundant financial resources.

\section{Injuries and road traffic accidents}

The incidence of road traffic accidents in the GCC has been a continuing public health issue. It is associated with a high fatality rate that is more than double that of Western nations (eg, Qatar has 28 fatalities per 100,000, the United Kingdom has 11.8, and the United States has 9.1). ${ }^{17}$ During the last decade, the rate of road traffic accidents in Qatar has increased by $160 \%$, giving the state the dubious distinction of having the highest global rate of traffic fatalities. ${ }^{18}$ Disturbingly, although the distribution of road traffic accident-associated injuries is clustered in the 10-40-year age group, the incidence of musculoskeletal injuries in the pediatric age group is extremely high and is associated with a lack of seatbelt use and speeding violations, despite existing legislation. ${ }^{19}$ In one study, $44 \%$ of these injuries occurred in children younger than 10 years, with concomitant closed-head and visceral injuries in $14 \%$ and $5 \%$ of these cases, respectively. ${ }^{20}$ Most of these injuries were a result of pedestrian collisions (43\%) or were passenger-related $(25 \%)$.

The trends in road traffic accident-related injury and death represent significant drivers for the medical technology market, particularly as it relates to the orthopedic trauma implant and advanced diagnostic imaging markets. In addition, although not specifically medical device-related, innovation at the source relating to the prevention of road 
traffic accidents is also an area of extreme importance to public health in the GCC and is a market opportunity.

\section{Consanguinity and genetic disorders}

Throughout the Middle East, consanguinity is commonplace and socially acceptable, particularly in the tribal-based societies found in the Arabian Gulf. Its high prevalence is reported to be "related to religion, race, ethnicity, and sociocultural factors", whereby these marriages were considered to be more stable because of similarities in family values and conservation of wealth. ${ }^{6}$ The rate of consanguineous unions is highest in Saudi Arabia, at 58\%; the remaining GCC states are at approximately $50 \%$. Because of an increased risk for recessive genetic diseases, this practice represents a significant health care burden for the GCC, leading to a higher incidence of childhood mortality and rare genetic disorders, and perhaps most important, an increase in polygenic common adult diseases, including diabetes mellitus, deafness, hypertension, cardiovascular disease, and certain cancers. ${ }^{9}$ Many of these disorders are already a significant health care burden in the Middle East because of lifestyle choices that are likely compounded by the effects of consanguinity.

There is significant demand for medical technologies that address the sequelae of these common polygenic disorders, particularly for diabetes surveillance and the treatment of its related diseases (including retinopathy, nephropathy, and neuropathy). Advances in ophthalmologic technologies and dialysis treatment would be two areas of potential interest in this regard.

\section{Medical device market and health care spending}

For the reasons discussed in the preceding sections, health care spending in the GCC continues to be strong and is expected to rise significantly. ${ }^{5}$ Despite their robust economies, in the countries making up the GCC, health care expenditure as a percentage of gross domestic product is considerably lower than in Western nations. In 2009, for example, Saudi Arabia's expenditure was 5\% compared with $16 \%$ in the United States. ${ }^{2}$ Within the GCC, Qatar has the highest per capita health care spending, at US\$1,715, which is still much lower than in the United Kingdom and the United States, at US\$3,285 and US\$7,410, respectively. The market for medical equipment and supplies, however, is largest in Saudi Arabia and the UAE, with a combined expenditure of approximately US $\$ 1.4$ billion, or $47 \%$ of the total GCC market. With the prevailing disease burden in the GCC on the rise, spending will have to increase to meet the demand. For medical devices alone, an annual growth rate of $5 \%$ is expected. ${ }^{2}$

The current medical device market in the GCC is primarily import-based, with $96 \%$ of medical equipment supplied by the United States and Germany and a total projected expenditure of US\$819 million in the UAE alone by the end of 2014. ${ }^{5}$ In Saudi Arabia, less than 3\% of the total expenditure on medical equipment is for local products that are typically limited to low-technology consumables, such as syringes and catheters. ${ }^{1}$ Although many of these local companies distribute within the GCC only, there are some successful companies, such as the Qatar German Company for Medical Devices, that export to several countries within Europe, Africa, and North America. Again, the focus for the Qatar German Company for Medical Devices, which is the Middle East's largest medical device manufacturer, is on low technology class 1 devices, but it does represent the potential for the development of a bigger market and for device manufacturing in the region.

Given the local disease burden and demand, the key subsectors within the GCC medical device market include cardiovascular devices (eg, implantable stents, pacemakers, and implantable defibrillators), dialysis machines, rehabilitation equipment, diagnostic equipment, and surgical implants and related instruments. ${ }^{5}$ Other than disease burden, there are additional circumstances/developments within the health care infrastructure that contribute to the increasing demand for medical technologies in the GCC.

\section{Health care infrastructure}

Although still firmly in the development phase, GCC member states are currently in the process of revitalizing their hospital systems in line with the increasing health awareness and expectations of their affluent populace. Despite increased expenditure, GCC states trail behind more developed nations with respect to the number of hospital beds and amount of diagnostic equipment, laboratory services, and trained medical personnel available. ${ }^{2}$ In addition, because of a shortfall in local medical education institutions and a paucity of GCC nationals entering medical professions, health care delivery in the GCC relies heavily on the presence of expatriate workers from Western nations and from the rest of the Arab world. In Saudi Arabia and the UAE, for example, $80 \%$ and $92 \%$ of all physicians are expatriates, respectively. With respect to the medical device industry, one benefit of this practice is that many Western-trained expatriate physicians will push for the procurement of the high-cost medical technologies with which they are familiar from their home countries. 
The rapid growth in the Gulf region has outstripped its local health care capacity, spurring a pattern of overseas medical tourism to access quality health care. At this time, many GCC nationals are subsidized heavily to seek care in academic health centers in North America, Europe, India, and Asia, with an annual associated expenditure of more than US $\$ 2$ billion for some states. ${ }^{2}$ It is recognized that these funds would be better spent enhancing the domestic health care system, rather than sending that money overseas. In an attempt to build local capacity and stem the outsourcing of medical care, GCC governments are investing heavily in health care megaprojects, such as the Sidra Medical and Research Center in Qatar and Sheikh Khalifa Medical City in the UAE, through strategic academic partnerships with world-class institutions such as Weill Cornell Medical College-Qatar and the Cleveland Clinic, respectively. In addition, many of these new institutions are accredited via the Joint Commission International, an entity that provides hospital certification confirming global standards of patient safety and quality. With these and other health-related costs increasing on a yearly basis, there have been initiatives to encourage the involvement of the private sector in the GCC and to go forward with national insurance schemes in most of the member states.

Despite the changing landscape, most health care models in the GCC rely on the public sector for approximately $75 \%$ of their funding, with the gap being filled by private health providers. The nations' respective ministries of health are responsible for the provision of health care services in each member state, in addition to their roles in the licensing of medical professionals and regulatory matters. In the state of Qatar, for example, the majority of health care is provided by the public system through the Hamad Medical Corporation. This large hospital network includes three general hospitals outside of the capital Doha (Al Khor Hospital, Al Wakra Hospital, and the Cuban Hospital), in addition to five specialist hospitals (Hamad General Hospital, Rumailah Hospital, the National Center of Cancer Care, the Heart Hospital, and the Women's Hospital) that cover the full scope of medical care for adults and children in this state of approximately 2 million inhabitants. These linked academic medical teaching institutions are affiliated with Weill Cornell Medical CollegeQatar (a branch campus of the New York-based university) and are the main source of medical care in the state. ${ }^{21} \mathrm{~A}$ further three affiliated hospitals are slated to open by the end of 2015, focused on rehabilitation, women's care, and ambulatory surgical care. All of the HMC hospitals are accredited by the Joint Commission International, and it was the first institution in the Middle East to receive Accreditation Council of Graduate Medical Education International (ACGME-I) status for its medical residency and fellowship teaching programs. The council is the world standard for the delivery of graduate medical education that determines compliance with global standards of educational quality for medical graduates. These efforts are focused on the further development of a self-sustaining well-trained medical workforce to help stem the reliance on foreign medical professionals to deliver health care to GCC citizens at home or abroad. ${ }^{22}$

The Hamad Medical Corporation is just one part of a larger academic health system that focuses on clinical work, research, and education by linking several institutions under a single umbrella. In Qatar, for example, there are seven collaborative academic health care partners including Sidra Medical and Research Center, Weill Cornell Medial CollegeQatar, Qatar Biomedical Research Institute, College of the North Atlantic, Primary Health Care Corporation, Qatar University, and the University of Calgary. This system was designed to support the National Health Strategy for the country, which supports the following key activities: develop a world-class health care system with universal access, provide high-quality medical care through an integrated network, focus efforts on the prevention of disease, assemble a skilled workforce capable of delivering high-quality care, and support research initiatives that feed back into improved care..$^{23}$ Similar models of collaboration between world-class facilities are underway, requiring a massive injection of health care spending in the region. In the UAE, the Abu Dhabi Health Services Company (otherwise known as "SEHA", which is Arabic for "health") was set up to partner with international players including the Cleveland Clinic (managing Sheikh Khalifa Medical City) and Johns Hopkins Medicine (managing Tawam, Al Rahba, and Corniche hospitals), in addition to others. Dubai Healthcare City's partnership with Harvard Medical International represents another example of a UAEbased academic medical system that taps the resources of an internationally respected entity to provide the governance and hospital infrastructure to deliver world-class care within the GCC. ${ }^{24}$ At present, Saudi Arabia has the most mature and comprehensive health care system in the region, but the other member states are jockeying to bring their systems to a comparable or higher level. All of this investment in state-ofthe-art facilities translates into favorable market conditions for medical devices. In particular, high-technology devices typically found in the world's most admired institutions are acquired to bring prestige (and patients) to these centers. This is contrary to current practices in North America and 
Europe, where cost-cutting measures make these technologies less easy to acquire, effectively stifling the market in favor of lower-technology, lower-cost devices.

In addition to the public hospital system, there is growing interest in developing the private hospital system in GCC member states. At this time, in Qatar, this part of the system is very small, with only one full-scope private hospital and several smaller medical centers to meet the demand for private services. With a growing need for additional medical infrastructure to meet current and future needs, GCC governments are actively encouraging participation from the private system to help offset the anticipated increase in expenditure. ${ }^{5}$ In addition, the recent introduction of national insurance schemes in the GCC is expected to increase demand even further, with patients being more apt to access medical services if they know they have coverage. The result of such initiatives will serve to increase the market for medical devices in the region as more patient choice and coverage improves (and encourages) access to comprehensive medical care.

\section{Reimbursement pathways The role of payers and insurance}

As discussed earlier, within the GCC, approximately 75\% of health care expenditure is publically funded through the respective ministries of health, with the remaining spending shouldered by the much smaller private health care systems. With a projected growth of expenditure of as high as 14\% per year, GCC governments are exploring different ways to bear these increasing health care costs. This increase in spending is mainly a result of a growing demand for services that necessitates investment in new infrastructure, medical technology acquisition, and hiring qualified medical professionals. ${ }^{33}$ At this time, within the GCC, there are two approaches to achieving a more economically beneficial distribution of expenditure: increasing the penetration of private health care institutions and embracing national health insurance programs. ${ }^{1}$

\section{Private health care}

As a result of dramatic population growth, increased disease burden, and rising medical costs, governments in the GCC are embracing the private sector via public-private partnerships, in addition to private-only institutions. ${ }^{2}$ In the public-private partnership model, appointing private players (typically international institutions) as managers of publically funded health facilities has been purported to improve infrastructure and provide a more cost-effective delivery of services by transplanting operating procedures and health system know-how into the GCC framework. For example, a successful public-private partnership (SEHA, The Abu Dhabi Health Services Company) has been implemented in Abu Dhabi, whereby eight health systems are managed under one umbrella organization with private partners, including Johns Hopkins and the Cleveland Clinic from the United States. ${ }^{25}$ By another mechanism, encouraging the establishment of private full-service health care facilities such as the Al Ahli Hospital in Doha serves to reduce capital investment requirements from the government purse and spur competition that will decrease prices and improve patient choice.

\section{National health insurance}

At only $1.3 \%$ (gross premium as a percentage of gross domestic product), health insurance penetration in the GCC is significantly lower than the global average of $7 \% .^{2}$ Even among emerging markets, the insurance penetration is more than double that of the GCC. The increasing interest in national health insurance programs in the GCC is rooted in the following potential benefits: it improves health care affordability for patients (eg, in Qatar, although the Qatari national population has full public coverage of health care costs, the remaining $75 \%$ of the population, including expatriates, does not); it will likely increase demand for private medical services as more costs are covered under insurance; with respect to the preceding point, it will serve to distribute costs between private and public entities; it will give patients more choice regarding medical providers; and it enables investment into quality improvement as the economic burden on government is eased.

Many GCC governments have already implemented national insurance programs. Saudi Arabia, for example, has had a mandatory health insurance program in place for expatriates since 2006, and the UAE has approximately $55 \%$ insurance penetration at present. ${ }^{2}$ In Qatar, the state is currently in the midst of a phased rollout of its National Health Insurance program. Under this program, the plan is to have the entire Qatari national population covered by the end of 2014, with the full resident population covered by the end of 2016. Coincident with this process is the development of a new unified medical coding system, applicable laws and regulations, a comprehensive fee schedule for medical services, and an integrated system for tracking patient data. $^{33}$

Responding to the increasing demand for health care services by allowing increased involvement of the private sector will likely have a beneficial effect on the medical device market simply by increasing patient access to care. In 
addition, from a medical device manufacturer's point of view, the implementation of mandatory national health insurance requirements has the potential to further boost demand for medical services that will, in turn, strengthen the market for medical devices.

\section{Medical coding for reimbursement}

Establishment of an effective medical coding system that accurately reflects the patient's diagnosis and the scope of the medical service provided to the patient is important, as it allows for the identification of patients with particular disease states/medical procedures for clinical audit and research purposes, a means of disease surveillance in time of epidemic or pandemic outbreaks, and a means to track and assign reimbursement for medical services delivered to a particular patient. ${ }^{23,26}$

In the United States, for both physicians and facilities to be paid for their services, standardized codes that document both the diagnosis and procedures performed are essential to justify the bill submitted to the payer (eg, Medicare, an insurance company, and so on). The payer then assesses whether or not the procedures/services described are covered under its policies. With respect to reimbursement pertaining to medical devices, the three most important coding systems involve the use of International Classification of Diseases (ICD) codes, which are used to describe diagnoses and procedures provided in facilities; Current Procedural Terminology (CPT) codes, used to describe procedures and services provided by medical professionals; and diagnosis-related group (DRG) codes, used to capture diagnosis and procedures performed as the basis for inpatient facility payments. ${ }^{27}$ For reimbursement related to medical devices, companies need to decide whether the existing codes (CPT, ICD-9 or ICD-10, and DRG codes) present in the regional medical system are adequate on their own or whether new codes need to be developed.

In the GCC, similar to in the United States and most other developed nations, comparable standardized coding systems have been adopted to allow for an accurate system of reimbursement from payers to providers. For the Dubai Health Authority in the UAE, for example, US-style coding systems have been adopted including ICD-10 (diagnosis), CPT 4 (medical, surgical, and diagnostic procedures), and Healthcare Common Procedure Coding System (HCPCS) level 2 (supplies and consumables) to allow for the processing of insurance claims. ${ }^{23}$ The Health Authority of Abu Dhabi has a similar system. ${ }^{28}$ In Saudi Arabia and Qatar, for both public and private providers, agreements between the GCC states and the Australian government have led to the adoption of ICD-10-AM (Australian Modification) and the Australian Refined DRG codes for capturing diagnosis and inpatient encounters, respectively. ${ }^{29}$

For medical device manufacturers, an understanding of the existing reimbursement-related codes within the region of interest is important to determine whether or not appropriate reimbursement for their device can be realized.

\section{Regulatory framework}

In addition to their role in funding health care, the ministries of health in each country are ultimately responsible for regulatory oversight. With respect to the medical device regulatory environment in the GCC, each member state has its own system in differing stages of maturity. Despite this, all GCC countries seem to understand the benefits of having a robust regulatory system that allows access while ensuring public safety. To this point, section 5.4 of the Qatar National Health Strategy states there is a duty to "ensure effective use, safety, and quality of healthcare products by enhancing health care products regulation". ${ }^{21}$ Ironically, Qatar has perhaps the least well-developed regulatory system in the GCC, but this is changing.

As a starting point in the regulatory pathway, all GCC member states have a requirement for overseas device manufacturers to appoint a local (or authorized) representative to facilitate the registration/regulation (in addition to distribution and sale) of their products with each country. Although there are many such commonalities between regulatory models within the GCC, there are also some significant differences that will be outlined in the following sections, along with a more detailed discussion of the role of the local representative.

\section{The role of local representatives}

The three GCC states that are the focus of this article all require the employ of a local or authorized representative (LR) as a liaison between the regulatory body and the device manufacturer. Overseas device manufacturers need to identify a representative based in the member country of interest who will be responsible for applying for device authorization through the local regulatory body, if present. The manufacturer must provide the LR with all the documentation needed to satisfy the requirements for application to the regulatory body. Local device manufacturers do not require any further representation and can communicate with the regulatory body directly. The typical activities of the LR include communicating with the regulatory body, applying for device approval through the regulatory body, cooperating with the 
regulatory body with respect to postmarket surveillance activities where required, informing the regulatory body of any adverse events associated with a device, informing the end users of any adverse events and taking corrective action to mitigate further events occurring, and cooperating with parties involved in the distribution and sale of the device within the state. ${ }^{30}$

The choice of local representative is a crucial one for the device manufacturer, as it is this entity that represents the company's face not only to the regulatory body but also to physicians, facilities procurement personnel, and other stakeholders. Choosing an LR that has well-established relationships with the local community and trained staff and who facilities an effective supply chain to support distribution and sale to local institutions, therefore, is critical.

\section{Saudi Arabia}

As previously discussed, the health care system in Saudi Arabia is the largest and most technologically advanced in the GCC. ${ }^{2}$ It would stand to reason, then, that its medical device regulatory system is advanced to a similar degree. In reality, the regulatory framework in still under development, but interim legislation is currently in place to meet the need until a comprehensive medical devices law has been established. ${ }^{31}$ The independent regulatory body responsible for the authorization of medical devices within Saudi Arabia is the Saudi Food and Drug Authority, or SFDA. The consistency of acronyms between the SFDA and its US cousin, the US Food and Drug Administration (US FDA), underestimates the scope of the body with respect to the rules governing the registration of medical devices in Saudi Arabia.

SFDA regulatory guidelines are based on preexisting approval in one of the five founding member nations of the Global Harmonization Task Force (GHTF; replaced by the International Medical Device Regulators Forum as of February 2011, including Australia, Canada, the United States, the European Union, and Japan), an organization established in 1992 to achieve greater uniformity among regulatory authorities with respect to enhancing access to safe and effective medical devices. ${ }^{32}$ As such, depending on the preapproving GHTF body, the requirements for authorization can be quite different. For example, devices preapproved by the US FDA would have likely gone through prior clinical and/or bench studies to prove both safety and effectiveness with respect to the medical device in question. For the purposes of the SFDA, however, there are no overt requirements for the provision of safety and effectiveness data in the form of clinical trials or other studies. As such, for companies interested solely in the Saudi Arabian market, obtaining a CE mark alone would be sufficient, which would likely be a shorter regulatory pathway for approval. All regulatory bodies within the GCC, however, require safety data, including information on intended use, warnings, precautions, and potential adverse events associated with this use.

In Saudi Arabia, regulatory authorization is required for all medical devices, regardless of device class (as determined by the classification system corresponding to the preapproving GHTF regulatory body). The only exception to this requirement is for medical devices that were designed and constructed by local health care facility staff for internal use. ${ }^{26}$ This stipulation might represent an incentive for medical device manufacturers to partner with local health care institutions to codevelop medical technologies for which early investigational data might be collected to support subsequent out-of-country regulatory approval. The ethics of such practice would require further discussions that are beyond the scope of this article.

Similar to its US counterpart, the SFDA has instituted postmarket surveillance requirements to ensure medical device safety and quality after introduction to the market. At the minimum, the user/manufacturer needs to maintain a database of safety and performance data through which adverse events are captured and subsequently communicated to the SFDA National Center for Medical Devices, end users, and other interested parties. As stated previously, this communication is managed and facilitated by the LR, and there is an expectation for "field safety corrective actions" to be implemented to prevent further adverse events. ${ }^{33}$

In addition to postmarket surveillance activities, the SFDA also has a mechanism whereby a device can be taken off the market even before it has been put into service. The mechanism is known as market control, and it can be initiated if the device has been found to compromise patient safety, to have been previously withdrawn from another market, to be not in full compliance with the SFDA medical device interim legislation, or to be in the process of corrective actions to rectify adverse events or noncompliance..$^{29}$

\section{The United Arab Emirates}

There are many similarities in the process of medical device registration between Saudi Arabia and the UAE, but there are also some key differences. To facilitate device registration in the UAE, an LR is required with the same responsibilities as described here for the SFDA. In addition, similar to Saudi Arabia, medical device registration is handled through a regulatory authority under the auspices of the Ministry of Health via (in the UAE) the Registration and Drug Control 
Department. This department has subsequently developed a guideline for medical device registration in the UAE designed to ensure devices meet "internationally accepted principles and requirements relating to their design, classification, manufacture, placing on the market, putting into service, and inspection". ${ }^{34}$ The guideline aims to strike a balance between patient access to potentially beneficial new medical technologies and ensuring product safety and effectiveness. In developing this guideline, the Registration and Drug Control Department included principles designed to simulate the pathways inherent to the European Union Medical Device Directive 93/42/EEC, the Active Implantable Medical Device Directive 90/385/EEC, Health Canada, the US FDA, and other entities. ${ }^{30}$ Unlike the requirements for European Union approval, however, applications for registration of medical devices in the UAE must include data on effectiveness in addition to safety (a nod to the requirements of the US FDA). As previously stated, the SFDA, however, does not have such a requirement. Documentation regarding certification of the device manufacturer's quality systems is also required in support of the application.

Another difference between UAE requirements for registration and the SFDA is the classification of medical devices. For the SFDA, the device classification is based on the corresponding system used by the regulatory body that gave preexisting approval. The UAE body, however, has its own device classification system that is most closely related to that used by the European Commission, defined as class 1, low risk; class 2, medium risk but nonimplantable; class 3, medium risk but implantable; and class 4 , high risk.

Regarding the requirements for postmarket activities under device registration in the UAE, the obligations to the SFDA are similar and require that procedures be in place to provide corrective actions as needed if adverse events are identified aftermarket launch. To capture adverse event data, as well as to maintain records of device distribution/sales, recalls, and compliance documentation, a Medical Device Vigilance System must be implemented and maintained (also advised by the SFDA). This system is used to maintain records of device distribution and sales, adverse events, recalls, and compliance documentation. ${ }^{35} \mathrm{With}$ respect to the use of medical devices, it is the responsibility of the health care institution to inform the manufacturer and the SFDA of any adverse events associated with this use.

\section{Qatar}

As stated in the National Health Strategy project update, it is recognized that "Qatar does not currently have an effective system to regulate the introduction and continued use of medical devices within the State." ${ }^{36}$ Despite the fact that Qatar has the least-developed regulatory system of the three largest economies in the GCC, there do exist some general guidelines with respect to medical device registration. Similar to Saudi Arabia, the regulatory guidelines for the registration of medical devices require prior approval in a GHTF nation. As with Saudi Arabia and the UAE, medical device registration in Qatar requires the services of a LR to communicate with the regulatory body. In Qatar, the Ministry of Economy and Commerce (MEC) receives and processes medical device applications. The LR must be a Qatari national and be registered with the Qatar Chamber of Commerce and Industry. From February 28, 2011, forward, devices not previously approved need to obtain a Qatar MEC Marketing Authorization before they can be distributed and sold in the country. Devices in use before this time may continue to be used. ${ }^{37}$ Regarding postmarket obligations and market control practices, there is little information with respect to those requirements currently in Qatar. Despite this, the National Health Strategy outlined by the state has identified comprehensive medical device regulation as a priority, and as such, we should expect to see these areas to tighten up in the near future. ${ }^{23}$

Despite the MEC "mark", the regulatory framework is still quite immature, with efforts ongoing to expand the scope of the Department of Pharmacy and Drug Control at Qatar's Supreme Council of Health to include medical devices and to develop appropriate standards to guide the process. As outlined in the National Health Strategy document, plans are underway for the development of an effective regulatory framework within the state, in cooperation with international partners. Under this strategy, a system is under development that will see " $100 \%$ of new medical devices...regulated by the end of 2015 ". 32

Given the newness of the GCC medical device market, robust regulatory frameworks that prevent the entry of unsafe devices are paramount. It being such a young industry, coupled with the lack of a cohesive GCC regulatory body, raises the risk for regulatory failures and the potential for patient harm. In addition, from a cost-effectiveness perspective, the institution of health technology assessment entities within the member states should be prioritized to help identify those medical devices associated with the best clinical results at the lowest cost. Medical device manufacturers will benefit from the knowledge of clear regulatory guidelines when preparing their applications for registration. Measures to develop a regional medical device authority with jurisdiction 
Table I Comparison of regulatory frameworks for Saudi Arabia, UAE, and Qatar

\begin{tabular}{|c|c|c|c|c|c|}
\hline GCC state & Basis of regulation & Regulatory body & $\begin{array}{l}\text { Classification } \\
\text { system used }\end{array}$ & $\begin{array}{l}\text { Post-market surveillance } \\
\text { requirements }\end{array}$ & $\begin{array}{l}\text { Need for local } \\
\text { representative }\end{array}$ \\
\hline Saudi Arabia & $\begin{array}{l}\text { Pre-existing approval in } \\
\text { one of GHTF founding } \\
\text { member countries }\end{array}$ & SFDA & $\begin{array}{l}\text { According to pre-existing } \\
\text { approval agency }\end{array}$ & $\begin{array}{l}\text { Required to maintain } \\
\text { a database of safety } \\
\text { and performance data; } \\
\text { Mechanism for corrective } \\
\text { actions as necessary }\end{array}$ & Yes \\
\hline UAE & $\begin{array}{l}\text { Based on guideline from } \\
\text { RDC; similar to EU but } \\
\text { absolute requirement } \\
\text { for both safety and } \\
\text { effectiveness data }\end{array}$ & $\begin{array}{l}\text { RDC under Ministry } \\
\text { of Health }\end{array}$ & $\begin{array}{l}\text { Own system, similar to } \\
\text { EU: Class I=low risk, } \\
\text { Class II=medium risk, } \\
\text { non-implantable, } \\
\text { Class III=medium risk, } \\
\text { implantable, } \\
\text { Class IV=high risk }\end{array}$ & $\begin{array}{l}\text { Required to maintain a } \\
\text { Medical Device Vigilance } \\
\text { System database; } \\
\text { Mechanism for corrective } \\
\text { actions as necessary }\end{array}$ & Yes \\
\hline Qatar & $\begin{array}{l}\text { Pre-existing approval in } \\
\text { one of GHTF founding } \\
\text { member countries }\end{array}$ & $\begin{array}{l}\text { Currently under MEC; } \\
\text { Plans to change to } \\
\text { Department of Pharmacy } \\
\text { and Drug Control (SCH) }\end{array}$ & $\begin{array}{l}\text { According to pre-existing } \\
\text { approval agency }\end{array}$ & Not specified & Yes \\
\hline
\end{tabular}

Abbreviations: GHTF, Global Harmonization Task Force; SFDA, Saudi Food and Drug Administration; RDC, Registration and Drug Control Department; MEC, Ministry of Economy and Commerce; SCH, Supreme Council of Health; UAE, United Arab Emirates; GCC, Gulf Cooperation Council; EU, European Union.

in each member state of the GCC would be advantageous in this regard.

The similarities and differences in regulatory frameworks for each of the three states discussed are summarized in Table 1 .

\section{Conclusion}

Despite an abundance of hydrocarbon-based wealth, the drivers of the medical device industry in the GCC are still in flux, with gains yet to be made in areas of infrastructure, regulation, and reimbursement. All indicators, however, suggest robust ongoing growth, in keeping with increases in population growth, disease burden, health care infrastructure, and insurance penetration. Coupled with improving "start-up" resources and increasing venture capital, the GCC would seem to represent fertile ground for the development of medical technologies, especially those in line with the regional health priorities of the respective member states.

\section{Acknowledgment}

Thank you to Professor Jan Pietzch (Stanford Biodesign, Faculty of Bioengineering, Stanford University, Palo Alto, CA, USA), who critically reviewed the study proposal and advised on study direction.

\section{Disclosure}

The author reports no conflicts of interest in this work.

\section{References}

1. Swiss Business Hub GCC. Medical Devices Market GCC. Dubai, UAE: Swiss Business Hub GCC; 2010. Available from: http://www.s-ge.com/ de/filefield-private/files/6529/field_blog_public_files/7963. Accessed May 15, 2014

2. Alpen Capital Investment Banking. GCC Healthcare Sector. Dubai, UAE: Alpen Capital Investment Banking; 2011. Available from: http://www.alpencapital.com/downloads/GCC $\% 20$ Healthcare $\% 20$ Sector_22\%20Apri1\%202014-\%20final.pdf. Accessed May 15, 2014

3. World Bank. GDP per Capita (Current US\$). Washington, DC: World Bank; c2014. Available from: http://data.worldbank.org/indicator/ NY.GDP.PCAP.CD. Accessed June 1, 2014

4. World Health Organization. World Health Statistics 2014. Geneva, Switzerland: World Health Organization; 2014. Available from: http:// www.who.int/mediacentre/news/releases/2014/world-health-statistics2014/en/. Accessed May 15, 2014.

5. General Secretariat for Development Planning. Advancing Sustainable Development: Qatar National Vision 2030. Doha, Qatar: 2009. Available from: http://planipolis.iiep.unesco.org/upload/Qatar/Qatar HDR_2009_English.pdf. Accessed May 15, 2014.

6. Trade Section of the Italian Embassy. UAE: Market Report: Medical Equipment. Dubai, UAE: Italian Trade Commission; 2011. Available from: http://www.ice.gov.it/paesi/asia/emirati/upload/159/Medical\%20 Equipment\%20Report,\%20Jan\%202011.pdf. Accessed June 1, 2014.

7. Bener A, Hussain R. Consanguineous unions and child health in the State of Qatar. Paediatr Perinat Epidemiol. 2006;20(5):372-378.

8. Bener A, Al-Suwaidi J, Al-Jaber K, Al-Marri S, Elbagi IE. Epidemiology of hypertension and its associated risk factors in the Qatari population. J Hum Hypertens. 2004;18(7):529-530.

9. Bener A. The neglected epidemic: road traffic accidents in a developing country, State of Qatar. Int J Inj Contr Saf Promot. 2005;12(1):45-47.

10. Bener A, Hussain R, Teebi AS. Consanguineous marriages and their effects on common adult diseases: studies from an endogamous population. Med Princ Pract. 2007;16(4):262-267.

11. Paying the price of affluence. Qatar Health. 2013;1(1):17-19. Available from: http://www.sch.gov.qa/health-features/qatar-health-issue-01/ qatar-health-issue-01. Accessed November 5, 2014. 
12. World Bank. Urban Population (\% of Total). Washington, DC: The World Bank; c2014. Available from: http://data.worldbank.org/indicator/ SP.URB.TOTL.IN.ZS. Accessed June 1, 2014.

13. Boumedjout H. Cardiovascular diseases on the increase in Arab states. Nat Middle East. Epub March 12, 2012.

14. Ng SW, Zaghloul S, Ali HI, Harrison G, Popkin BM. The prevalence and trends of overweight, obesity and nutrition-related non-communicable diseases in the Arabian Gulf States. Obes Rev. 2011;12(1):1-13.

15. Popkin BM. Global nutrition dynamics: the world is shifting rapidly toward a diet linked with noncommunicable diseases. Am J Clin Nutr. 2006;84(2):289-298.

16. Parmar A. North American Obesity Market to Swell to $\$ 139.5 B$ by 2017, Spells Opportunity for Device Makers. Santa Monica, CA: MD + DI Magazine; 2013. Available from: http://www.mddionline com/article/north-american-weight-lossobesity-management-marketswell-1395-billion-2017. Accessed June 1, 2014.

17. Bener A. The neglected epidemic: road traffic accidents in a developing country, State of Qatar. Int J Inj Contr Saf Promot. 2005; $12(1): 45-47$.

18. Nehlawi M. The price of Qatar's high road accidents. Doha, Qatar: The Edge; 2013. Available from: http://www.theedge.me/the-price-of-qatarshigh-road-accidents/. Accessed June 1, 2014.

19. Burgut HR, Bener A, Sidahmed H, Albuz R, Sanya R, Khan WA. Risk factors contributing to road traffic crashes in a fast-developing country: the neglected health problem. Ulus Travma Acil Cerrahi Derg. 2010;16(6):497-502.

20. Bener A, Justham D, Azhar A, et al. Femoral fractures in children related to motor vehicle injuries. J Orthop Nurs. 2007;11(3):146-150.

21. www.hmc.org.qa [homepage on the Internet]. Doha, Qatar: Hamad Medical Corporation; 2014. Available from: http://www.hmc.org.qa/ en/. Accessed June 1, 2014.

22. http://www.acgme-i.org/web/index.html [homepage on the Internet]. Chicago, IL: Accreditation Council for Graduate Medical Education International; 2014 [updated February 14, 2014]. Available from: https:// www.acgme-i.org/web/index.html. Accessed June 1, 2014.

23. Supreme Council of Health. National Health Strategy 2011-2016: Caring for the Future: Executive Summary Update 2013. Doha, Qatar: General Secretariat, Supreme Council of Health; 2013. Available from: http://www.nhsq.info/app/media/325. Accessed November 5, 2014.

24. Crone RK. Flat medicine? Exploring trends in the globalization of health care. Acad Med. 2008;83(2):117-121.

25. Abu Dhabi Health Services Co Formation of SEHA. Abu Dhabi, UAE: SEHA; 2014. Available from: http:/www.seha.ae/seha/en/Pages/SehaFormation.aspx. Accessed June 1, 2014.
26. Dubai Medical Coding Task Force. Dubai Medical Coding Guidelines. Dubai, UAE: Dubai Health Authority; 2012 [updated April 1, 2012]. Available from: https://www.eclaimlink.ae/downloads/Coding Guidelines.pdf. Accessed June 1, 2014.

27. Zenios S, Makower J, Yock P, et al. Reimbursement Basics. In: Zenios S, Makower J, Yock, P, et al, editors. Biodesign: The Process of Innovating Medical Technologies. New York: Cambridge University Press; 2010:299-339.

28. Abu Dhabi, UAE: Health Authority, Abu Dhabi. Standards and Procedures Guidance; 2008 [updated Jan 2008]. Available from: http:// www.haad.ae/HAAD/Portals/0/Health\%20Insurance/Circulare/Circular\%20No.\%20(13)\%20for\%2030.1.2008.pdf. Accessed June 1, 2014.

29. Ministry of Health. ICD-10-AM: Introduction. Riyadh, Saudi Arabia: Ministry of Health; 2013 [updated January 22, 2013]. Available from: http://www.moh.gov.sa/en/HICC/ICD10AM/Pages/Introduction.aspx. Accessed June 1, 2014.

30. Medical Devices Sector-Saudi Food and Drug Authority. SFDA Medical Devices Sector MDS-G3 Document Guidance for Device Authorized Representatives. Umm Al-Qura J. 2009;(86):4249.

31. Emergo. Resource Library for Medical Device Professionals. Cairo, Egypt: Emergo; 2014. Available from: http://www.emergogroup.com/ resources/regulations-saudi-arabia. Accessed June 1, 2014.

32. International Medical Device Regulators Forum. GHTF Archive. Available from: http://www.imdrf.org/ghtf/ghtf-archives.asp.

33. Medical Devices Sector-Saudi Food and Drug Authority. SFDA Medical Devices Sector MDS-G6 Document-Guidance For Post-Market Surveillance. Umm Al-Qura J. 2009;(86):4249.

34. Al-Bariki F. Medical Device Registration Guideline. Registration and Drug Control Department Dubai, UAE: Ministry of Health; 2011. Available from: http://www.cpd-pharma.ae/downloads/4-Medical\%20 Device/MD\%20guide\%20line.pdf. Accessed June 1, 2014.

35. Medical Device Registration in the United Arab Emirates. Dubai, UAE: Arab Medico; 2011. Available from: http://www.azhari-law.com/ registration.pdf. Accessed June 1, 2014.

36. Supreme Council of Health. Qatar National Health Strategy 2011-2016: Project Implementation Update. Doha, Qatar: General Secretariat, Supreme Council of Health; 2013.

37. Arazy Group Consultants Inc. Medical Device Registration in Qatar Vancouver, Canada: Arazy Group Consultants Inc.; 2013. Available from: http://www.arazygroup.com/medical_device_registration_in_ qatar_. Accessed June 1, 2014.

38. 123rf.com [homepage on the Internet]. Vector - Kingdom of Saudi Arabia. Pavalena. Available from: http://www.123rf.com/ photo_14459935_kingdom-of-saudi-arabia.html. Accessed November $11,2014$.
Medical Devices: Evidence and Research

\section{Publish your work in this journal}

Medical Devices: Evidence and Research is an international, peerreviewed, open access journal that focuses on the evidence, technology, research, and expert opinion supporting the use and application of medical devices in the diagnosis, treatment and management of clinical conditions and physiological processes. The identification of novel

\section{Dovepress}

devices and optimal use of existing devices which will lead to improved clinical outcomes and more effective patient management and safety is a key feature. The manuscript management system is completely online and includes a quick and fair peer-review system. Visit http://www. dovepress.com/testimonials.php to read real quotes from authors. 